\title{
RANCANG BANGUN ALAT PENGADUK BUBUR OTOMATIS MENGGUNAKAN SENSOR SUHU BERBASIS ARDUINO UNO
}

\author{
Thamrin $^{1}$ \\ Delsina Faiza ${ }^{2}$ \\ IImiyati Rahmy Jasril ${ }^{3}$
}

\begin{abstract}
The aim of this research is to design and make stirring tool of corn grits with rotation speed of stirring based on temperature rise level detected by temperature sensor. Arduino Uno as reader of input data from temperature sensor and set output in the form of motor rotation stirrer, LCD display and buzzer. The benefits of this research in the field of application of electronics sensors in food processing, especially the effective and efficient corn grits processing. Both in terms of time, cost, energy and safety.
\end{abstract}

Keywords: Designing, Stirring, Corn Grits, Arduino Uno, Sensor

\section{INTISARI}

Penelitian ini bertujuan merancang dan membuat alat pengaduk bubur jagung dengan kecepatan putaran pengadukan berdasarkan tingkat kenaikan suhu yang dideteksi sensor suhu. Arduino Uno sebagai pembaca data input dari sensor suhu dan mengatur output berupa putaran motor pengaduk, tampilan LCD dan buzzer. Manfaat dari penelitian ini dalam bidang penerapan sensor elektronika pada pengolahan pangan khususnya pengolahan bubur jagung yang efektif dan efisien. Baik dari segi waktu, biaya, energi dan keselamatan kerja.

Kata Kunci: Merancang, Pengaduk, Bubur Jagung, Arduino Uno, Sensor

\footnotetext{
${ }^{123}$ Fakultas Teknik Universitas Negeri Padang
} 


\section{PENDAHULUAN}

Perkembangan ilmu pengetahuan dan teknologi yang demikian pesat, telah membawa manfaat bagi kemajuan peradaban umat manusia. Jenis-jenis pekerjaan yang sebelumnya menuntut kemampuan fisik yang cukup besar, saat ini sudah digantikan oleh perangkat mesin otomatis. Jenis pekerjaan yang manual dapat dijadikan otomatis untuk mempermudah kegiatan dan mengurangi pemakaian tenaga manusia. Pemanfaatan teknologi tersebut salah satunya adalah pada proses pengolahan pangan menjadi makanan siap saji.

Salah satu jenis makanan yang memerlukan pengolahan adalah bubur. Bubur merupakan makanan hasil olahan yang dibuat berbentuk adonan dan tekstur lunak. Tekstur

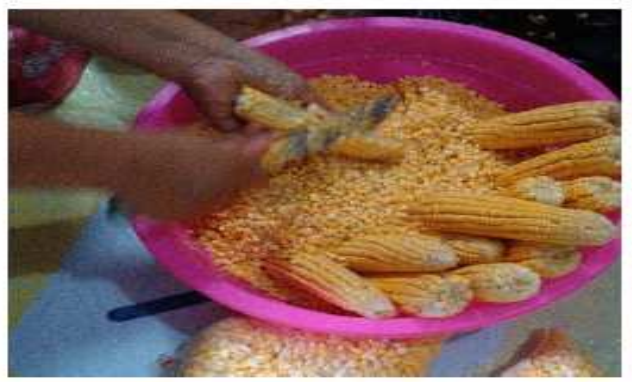

I (a) yang lunak akan memudahkan tubuh dalam proses pencernaannya. Salah satu jenis bubur yang tersedia dan banyak dikonsumsi masyarakat saat ini adalah dari bahan dasar jagung atau disebut dengan bubur jagung.

Proses pembuatan bubur jagung diawali dengan memisahkan biji jagung dari tongkolnya seperti terlihat pada gambar 1.a. Selanjutnya biji jagung dicampur dengan air secukupnya dan dihancurkan sampai menjadi larutan dengan menggunakan mixer (gambar 1.b). Larutan tersebut kemudian ditambah dengan gula dan vanile untuk mendapatkan rasa yang diinginkan. Proses selanjutnya adalah memanaskan larutan jagung tersebut dengan kompor sampai larutan mengental menjadi bubur jagung.

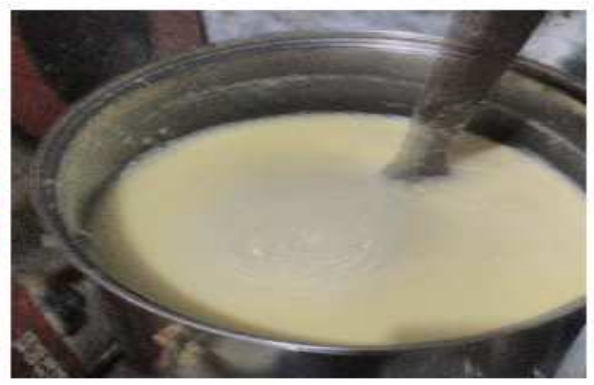

I (b)

Gambar 1. Proses Pemisahan Biji dari Tongkol dan Larutan Jagung

Proses pemanasan larutan jagung menjadi bubur memerlukan waktu selama lebih kurang 45 menit. Selama pemanasan, larutan jagung harus selalu diaduk dengan pengaduk untuk menjaga agar larutan tetap homogen dan tidak mengendap pada dasar panci seperti pada gambar 2.a. Selain itu pengadukan juga berfungsi agar larutan tidak gosong. Kecepatan pengadukan perlu disesuaikan dengan keadaan masakan.

Pada awal pemasakan hanya diperlukan kecepatan yang relatif kecil karena hanya untuk menjaga agar larutan tidak mengendap. Akan tetapi pada saat bubur mendekati matang perlu kecapatan yang lebih agar masakan tidak gosong seperti gambar 2.b. serta kekuatan pengadukan yang 
lebih besar seiring dengan kekentalan bubur.

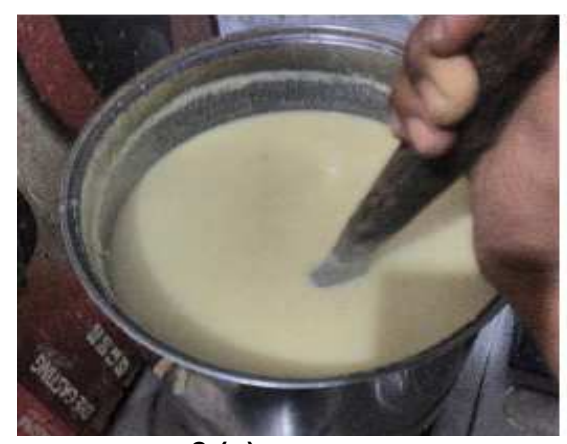

2 (a)

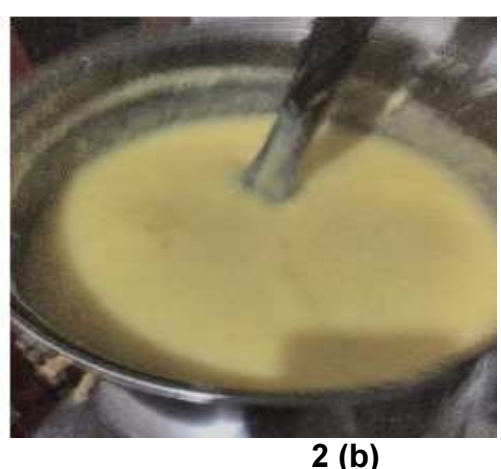

2 (b)

Gambar 2. Kondisi bubur pada awal pemasakan dan matang.

\begin{abstract}
Pengadukan bubur masih dilakukan secara manual oleh tenaga manusia sehingga bisa dikatakan kurang efesien dan efektif karena harus ditunggu terlebih dahulu agar tidak gosong, ditambah resiko dari pengadukan manual bisa menyebabkan terkena percikan bubur panas sehingga membahayakan keselamatan.
\end{abstract} Disamping itu, untuk memastikan kematangan bubur hanya diamati dari fiisk adonan bubur dengan mengamati gejala warna dan letupan bubur. Wadah pengadukan yang terbuka juga menyebabkan panas terbuang keluar sehingga menambah waktu pemasakan. Posisi panci pemasakan juga sangat rentan terjadinya pergeseran saat terjadi pengadukan sehingga relatif tidak aman bagi makanan dan pengguna.

Berdasarkan kenyataan diatas, dirasa perlu untuk merancang sebuah alat pengaduk bubur yang berteknologi tepat guna yang dapat membantu pekerjaan manusia dan relatif lebih aman terhadap pengguna dan masakan.

\section{PENDEKATAN MASALAH}

Dalam penelitian ini akan dirancang sebuah alat pengaduk bubur otomatis menggunakan sensor suhu berbasis Arduino Uno. Sensor suhu digunakan sebagai input untuk pendeteksi suhu pengadukan bubur, Pemproses sistem menggunakan Arduino Uno, dan output berupa jumlah putaran I rotasi per menit (rpm) pengaduk bubur dengan mengatur kecepatan motor.

\section{Karakteristik Bubur Jagung} Jagung adalah bahan pangan alternatif pengganti beras dan gandum yang perannya sangat vital dalam pencapaian swasembada pangan bagi masyarakat. Dari kondisi ini maka yang harus dapat dipenuhi yaitu penyediaan bahan pangan dan verifikasi olahan pangan. Jagung merupakan salah satu bahan pangan yang dapat dikelola seperti minyak jagung, sirup jagung, bubur jagung, gula jagung dan masih banyak lagi pengolahan jagung lainnya.

Bubur jagung merupakan makanan lembek dan berair yang terbuat dari bahan jagung dan santan yang dimasak hingga mendidih. Menurut Fatsecret dalam 1 mangkok bubur jagung 
memiliki kandungan gizi seperti ditunjukkan pada gambar 3. berikut.

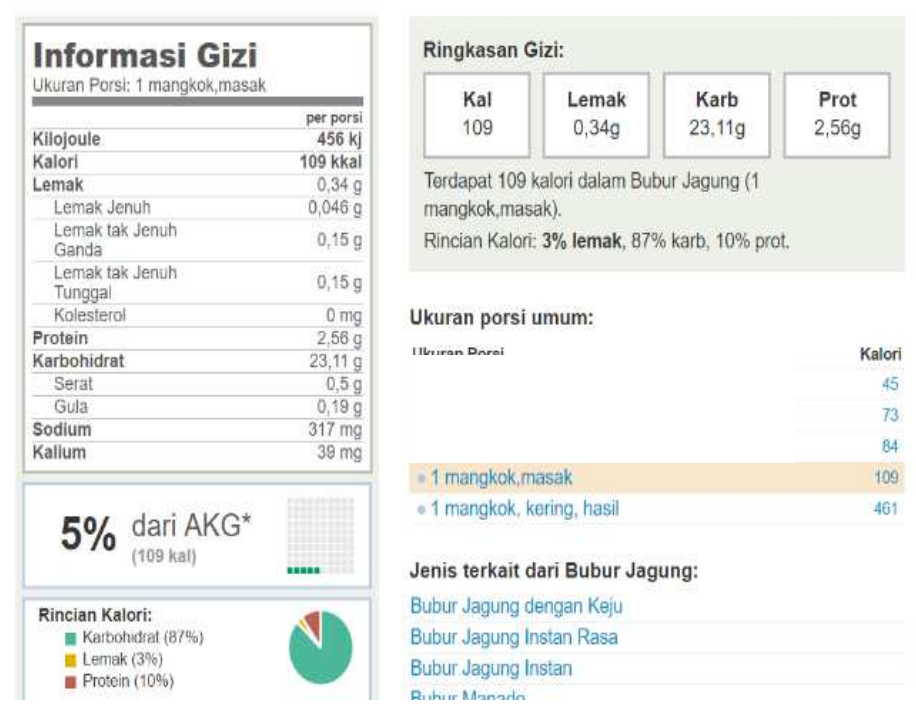

Gambar 3. Kandungan Gizi Bubur Jagung

Sumber : https://www.fatsecret.co.id/kalori-gizi/umum/bubur-jagung

\section{Sensor suhu DHT 11}

Sensor adalah peralatan yang digunakan untuk mendeteksi perubahan besaran fisis menjadi perubahan besaran listrik. Output sensor dapat berupa tegangan, arus, tahanan atau data. Beberapa sensor dapat juga berbentuk sistem sensor yang telah lebih komplit. Output sensor selanjutnya dapat diproses oleh kontroler sesuai dengan kebutuhan sistem yang direncanakan.

Besaran yang akan
disensor pada penelitian ini adalah suhu. Sensor yang digunakan adalah DHT11. DHT11 adalah suatu sensor gabungan besaran suhu dan kelembaban relatif yang menghasilkan output sinyal digital terkalibrasi. Bentuk fisik sensor dan konfigurasi pin sensor DHT11 terlihat pada gambar 4 dan tabel 1.

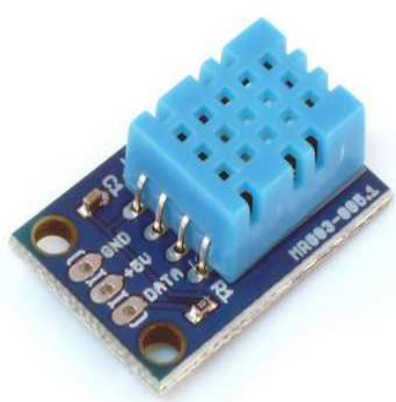

Gambar 4. Sensor suhu DHT11.

Tabel 1. Konfigurasi Pin DHT11

\begin{tabular}{|l|l|}
\hline Data & $\begin{array}{l}\text { Serial data } \\
\text { output }\end{array}$ \\
\hline GND & Ground \\
\hline$+5 \mathrm{~V}$ & $\begin{array}{l}\text { Power supply } \\
5 \mathrm{~V}\end{array}$ \\
\hline
\end{tabular}

Sumber: www.microbot.it.

3. Arduino Uno

Menurut

Firmansyah

(2015:1) "Arduino adalah papan rangkaian elektronik open source 
yang didalamnya terdapat komponen utama yaitu sebuah chip mikrokontroler."

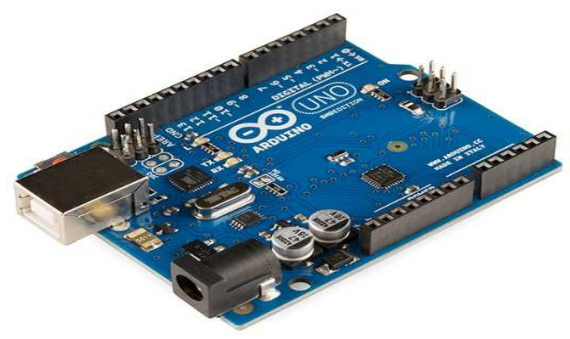

\section{Gambar 5. Arduino Uno}

Arduino Uno terdiri dari mikroprosesor dan dilengkapi dengan oscillator $16 \mathrm{MHz}$, dan regulator (pembangkit tegangan) 5 volt. Pada papan arduino uno terdapat beberapa pin input dan output yaitu pin 0 hingga 13 digunakan untuk sinyal digital,

\section{Tabel 2 : Spesifikasi Arduino UNO}

Sumber : www.microbot.it.

\begin{tabular}{|l|l|}
\hline \multicolumn{1}{|c|}{ Mikrokontroler } & ATmega328 \\
\hline $\begin{array}{l}\text { Tegangan yang } \\
\text { direkomendasikan }\end{array}$ & $7-12$ Volt \\
\hline Diaital I/O Pin & 14 (6 pin \\
\hline Analog Input Pin & 6 \\
\hline Arus DC per pin I/O & $40 \mathrm{~mA}$ \\
\hline $\begin{array}{l}\text { Arus DC untuk pin } \\
\text { 3.3V }\end{array}$ & $50 \mathrm{~mA}$ \\
\hline Flash Memory & $\begin{array}{l}32 \mathrm{~KB} \\
\text { (ATmega328) }\end{array}$ \\
\hline SRAM & $\begin{array}{l}2 \mathrm{~KB} \\
\text { (ATmega328) }\end{array}$ \\
\hline FFPROM & $1 \mathrm{~KB}$ \\
\hline Clock Speed & $16 \mathrm{~Hz}$ \\
\hline
\end{tabular}

\section{Motor AC Satu Fasa}

Motor Alternating Current (AC) adalah motor yang dapat bekerja menggunakan tegangan AC. Motor yang hanya bernilai 0 atau 1 . Pin $A 0$ hingga A5 digunakan untuk sinyal analog.

Arduino uno merupakan salah satu jenis rangkaian mikrokontroler yang menggunakan sistem physical computing. Physical computing adalah sebuah sistem atau perangkat fisik dengan menggunakan software dan hardware yang sifatnya interaktif yaitu dapat menerima rangsangan dari lingkungan dan dapat merespon balik. Arduino adalah kombinasi dari hardware, bahasa pemrograman dan Integrated Development Environment (IDE). IDE adalah sebuah software yang sangat berperan untuk menulis program, meng-compile menjadi kode biner dan meng-upload ke dalam memory mikrokontroler.

AC satu fasa terdiri dari dua komponen yaitu stator dan rotor. Stator adalah bagian dari motor yang tidak bergerak sedangkan rotor adalah bagian motor yang bergerak yang bertumpu pada bantalan poros terhadap stator (Akhmad: 2013). Motor yang paling sering digunakan pada berbagai peralatan di dunia industri adalah motor induksi.

a. Konstruksi Motor Induksi Satu Fasa Konstruksi motor AC satu fasa ditunjukkan gambar 6 . berikut:

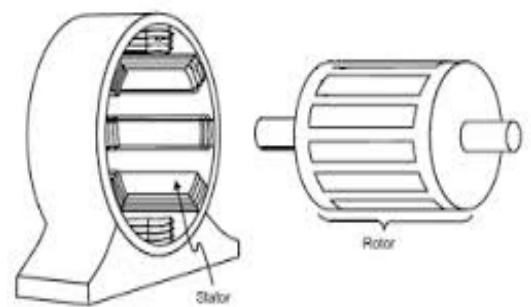

Gambar 6. Konstruksi Motor Induksi 1 Fasa (Sumber: Akhmad, 2013)

b. Prinsip Kerja Motor AC Satu Fasa 
Menurut Joko (2010: 5) "Sebuah Sebuah motor AC induksi satu fasa bergantung pada komponen listrik tambahan untuk menghasilkan ini berputar medan magnetik. Dua set elektromagnet dibentuk dalam setiap motor". Dalam motor induksi AC, satu set dari elektromagnet adalah terbentuk dalam stator karena pasokan $\mathrm{AC}$ terhubung ke gulungan stator. Sifat bergantian pasokan menginduksi sebuah tegangan Angkatan elektromagnetik (EMF) di rotor (seperti tegangan yang disebabkan akibat trafo sekunder) sesuai hukum Lenz, sehingga menghasilkan satu set elektromagnet; maka nama - induksi motor. Interaksi antara medan magnet elektromagnet ini menghasilkan gaya memutar, atau torsi. Akibatnya, motor berputar ke arah torsi yang dihasilkan.

\section{Triac sebagai Switching tegangan AC}

Triac (Triode for Alternating Current) merupakan komponen elektronika berupa piranti Thyristor bidirectional yang dapat bekerja pada rangkaian arus bolak-balik AC. Triac adalah tipe Silicon Controlled Rectifier (SCR) yang bekerja secara bidirectional. Triac memiliki sebuah terminal Gate (G) yang digunakan sebagai pemicu (trigger) pra tegangan maju (Herlan: 2009). Konfigurasi Triac dapat dilihat pada gambar 7 dibawah ini.

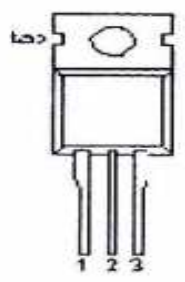

Gambar 7 Konfigurasi Triac (Sumber : Susatyo, 2007: 154)

Triac mempunyai tiga terminal yaitu; dua terminal utama $\mathrm{MT}_{1}$ dan
$\mathrm{MT}_{2}$ dan Gerbang (G). Simbol Rangkaian Triac seperti ditunjukkan pada gambar 8 berikut.

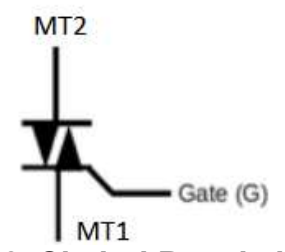

Gambar 8. Simbol Rangkaian Triac (Sumber : Herlan, 2009: 15)

Terminal $\mathrm{MT}_{1}$ dan $\mathrm{MT}_{2}$ dapat mengalirkan arus dua arah. Karena berinteraksi dengan gerbang $(\mathrm{G}), \mathrm{MT}_{1}$ digunakan sebagai pengukuran terminal referen. Arus dapat mengalir antara $\mathrm{MT}_{1}$ dan $\mathrm{MT}_{2}$ dan antara gerbang dengan $\mathrm{MT}_{1}$ (Andi, 2011: 2).Triac dapat di trigger agar konduksi pada salah satu arah dengan arus gerbang bergerak masuk atau keluar gerbang. Apabila aliran arus terminal utama ditentukan, Triac pada dasarnya mempunyai karakteristik pengoperasian internal sama seperti SCR. Rangkaian Ekuivalen Triac seperti ditunjukkan pada gambar 9 berikut.

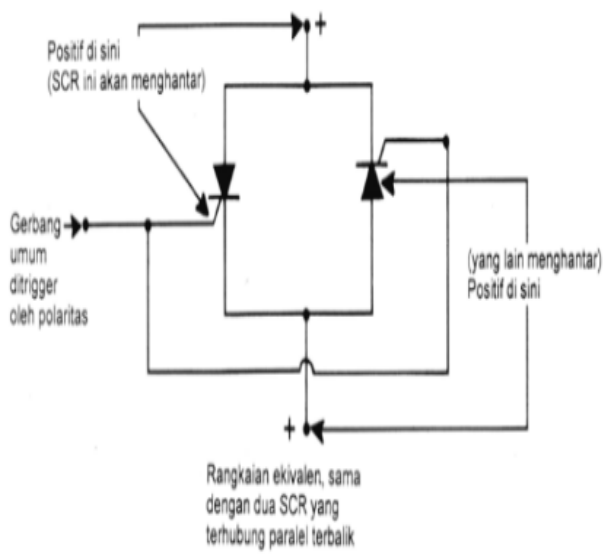

Gambar 9. Rangkaian Ekuivalen Triac

(Sumber : Andi, 2011: 2)

Aplikasi Triac yang digunakan pada rangkaian penghubung Triac dari sumber AC dapat dilihat pada gambar 10 berikut. 


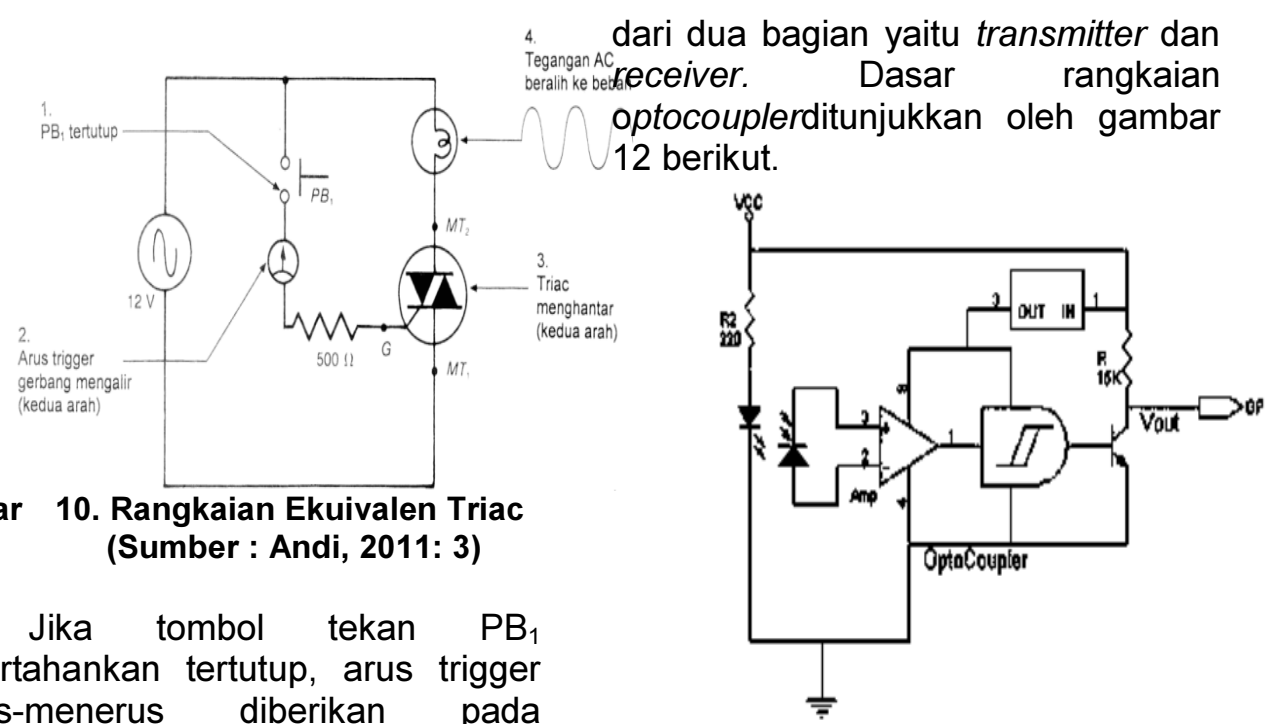
dipertahankan tertutup, arus trigger terus-menerus diberikan pada gerbang. Triac menghantarkan pada kedua arah untuk menghubungkan semua tegangan $A C$ yang diberikan pada beban. Jika tombol tekan dibuka, Triac kembali mati atau OFF, apabila tegangan sumber $A C$ dan penahanan arus turun menjadi nol atau polaritas terbalik. Perhatikan bahwa tidak seperti output dari rangkaian SCR yang sama, output rangkaian ini adalah arus $A C$, bukan searah.

\section{Optocoupler \\ Optocoupler adalah suatu sensor. Optocoupler dibuat menggunakan polimer semikonduktor. Struktur Geometrik Optokopler Polimer ditunjukkan oleh gambar 11 berikut.}

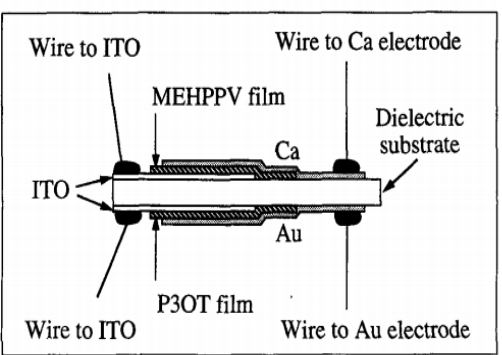

Gambar 11. Struktur Geometrik Optokopler Polimer

(Sumber : Yu, 1994: 926)

Optocoupler dapat bekerja berdasarkan picu cahaya dan terdiri

\section{Gambar 12. Rangkaian Optokopler}

(Sumber : Priyono, 2009: 2)

Bagian pemancar dibangun dari sebuah LED infra merah untuk mendapatkan ketahanan yang lebih baik dari pada menggunakan LED biasa dan phototransistor sebgai penerima cahaya. Phototransistor sebagai saklar yang dikendalikan oleh cahaya LED. Output dari optocouplemanya dua macam tegangan, bila tegangan input yang masuk lebih besar dari tegangan referensi maka keluaran optocoupler adalah sebesar Vcc. Dan jika sebaliknya, maka keluaran optocoupler adalah sebesar 0 Volt.

\section{Zero Crossing Detector (ZCD)}

Rangkaian ZCD berfungsi untuk mengetahui titik nol dari gelombang sumber generator AC. Hal ini diperlukan untuk menentukan kapan sudut penyalaan pada Triac dimulai. Rangkaian lengkapnya ditunjukkan oleh gambar 13. berikut. 


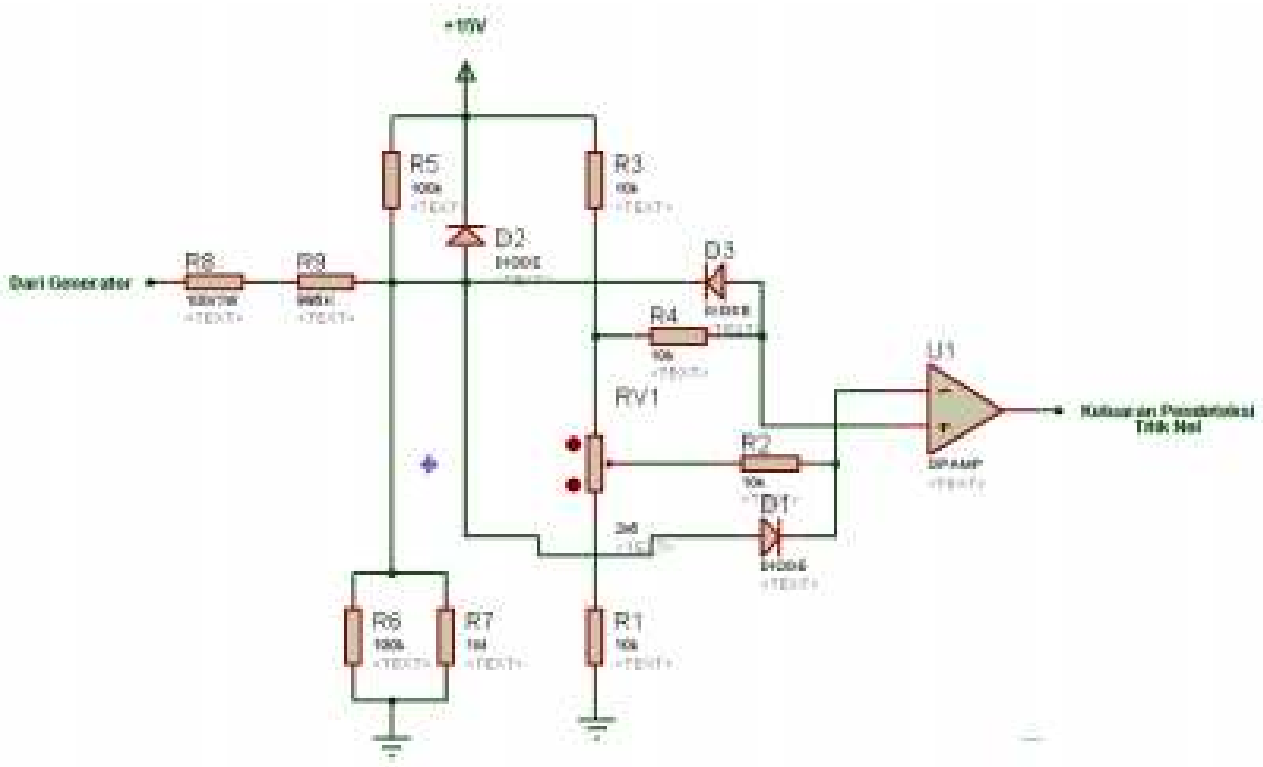

Gambar 13. Rangkaian ZCD

(Sumber : Machmud, 2009: 73)

\section{Bahasa Pemrograman}

Pemrograman Arduino dapat menggunakan low level language (assembly) dan high level language (C, Basic, Pascal, dan JAVA) tergantung compiler yang digunakan. Bahasa Assembler mikrokontroler AVR memiliki kesamaan instruksi, sehingga jika pemrograman satu jenis mikrokontroler AVR sudah dikuasai, maka akan mudah menguasai pemrograman keseluruhan mikrokontroler jenis mikrokontroler AVR.

\section{METODE PENELITIAN}

Metode yang digunakan pada penelitian ini terdiri dari beberapa tahap diantaranya :

\section{Tahap analisis}

Kegiatan analisis dilakukan melalui kegiatan studi lapangan dan studi literatur. Studi lapangan dilakukan dengan cara observasi langsung ke tempat usaha pembuatan bubur jagung yang akan digunakan untuk penelitian. Observasi yang dilakukan adalah dengan mewawancarai pemilik usaha tentang proses pembuatan bubur jagung. Tujuan dari observasi untuk menentukan kebutuhan alat pengaduk otomatis yang tepat untuk bubur jagung.

Analisis berikutnya dengan kegiatan studi literatur. Studi literatur dengan cara melakukan kajian teori melalui buku-buku dan sumber informasi lainnya berkaitan dengan rancang bangun alat pengaduk bubur otomatis.

2. Tahap Desain (Design)

Tahap desain merupakan langkah untuk merencanakan pembuatan alat pengaduk bubur sesuai dengan permasalahan yang ditemukan saat tahap analisis. Tahap desain meliputi tiga tahap yaitu:

a. Desain perangkat keras (hardware) 
Dalam perancangan dan pembuatan suatu sistem, dibutuhkan suatu blok diagram yang dapat menerangkan sistem secara keseluruhan. Setiap blok memiliki fungsi tertentu yang saling berkaitan sehingga membentuk sistem dari perangkat yang dibuat, seperti yang ditunjukan oleh blok diagram berikut :

Gambar14. Rancangan blok diagram sistem diagram

Fungsi masing-masing blok

1) Sensor Suhu

Digunakan sebagai pendeteksi besaran suhu pada wadah masakan yang akan menjadi data input kontroler. Sensor yang digunakan adalah DHT 11.

2) Kontroler

Berfungsi sebagai pengolah data dari sensor dan pengontrol seluruh output. Jenis kontroler yang digunakan adalah arduino uno.

3) Rangkaian Driver

Sebagai rangkaian penggerak, untuk mengendalikan Motor, heater dan buzzer.

4) Peraga
Peraga digunakan sebagai alat bantu visual untuk menampilkan data suhu yang dideteksi sensor. Jenis peraga yang digunakan adalah LCD $2 \times 16$.

5) Indikator suara.

Untuk memberikan informasi bahwa bubur telah masak.

b. Perancangan perangkat lunak (Software).

Perancangan perangkat lunak (software) diawali dengan perancangan diagram alir (flowchart) sistem. Rancangan flowchart alat pengaduk bubur otomatis menggunakan sensor suhu berbasis Arduino Uno adalah sebagai berikut : 


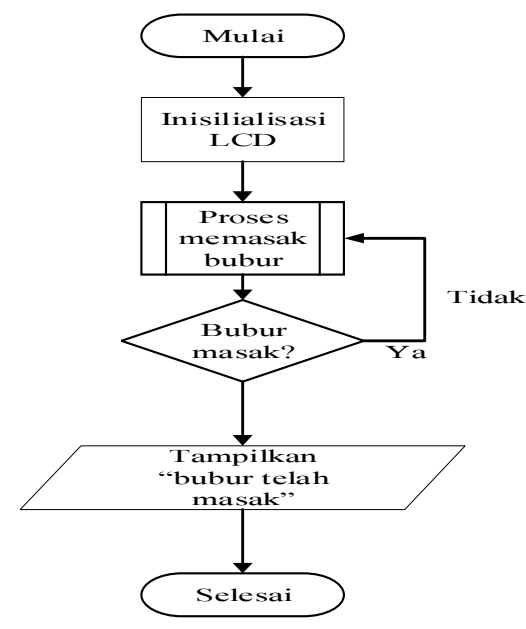

Gambar 15. Alur pemrograman alat pengaduk bubur otomatis.

Selanjutnya dibuat program menggunakan bahasa $C$ sesuai dengan rancangan sistem dan mengupload kedalam mikrokontroler.

c. Perancangan mekanik alat.

Pada tahap ini dirancang mekanik alat yang sesuai dengan kebutuhan sistem.

1. Pembuatan Alat.

Pembuatan alat pengaduk bubur jagung otomatis terbagi meliputi pembuatan hardware, software dan mekanik. Setelah ketiga bagian tersebut selesai maka dilanjutkan dengan mengintegrasikan menjadi kesatuan alat yang utuh sebelum dilakukan pengujian.

2. Pengujian.

Pengujian dilakukan untuk mengukur dan mengamati parameter kerja alat meliputi hardware, software dan mekanik. Pada tahap ini diamati apakah alat telah bekerja sesuai dengan rancangan.

3. Penerapan.

Pada tahap ini alat diterapkan pada produk bubur dan dilakukan pengukuran parameter kerja. Selain itu juga dilakukan pengulangan percobaan dengan memvariasikan beberapa parameter.

\section{Hasil Penelitian}

1. Pembuatan hardware.

Hasil pembuatan pada tahap ini didapatkan skematik rangkaian alat pengaduk bubur seperti terlihat pada gambar di bawah. 


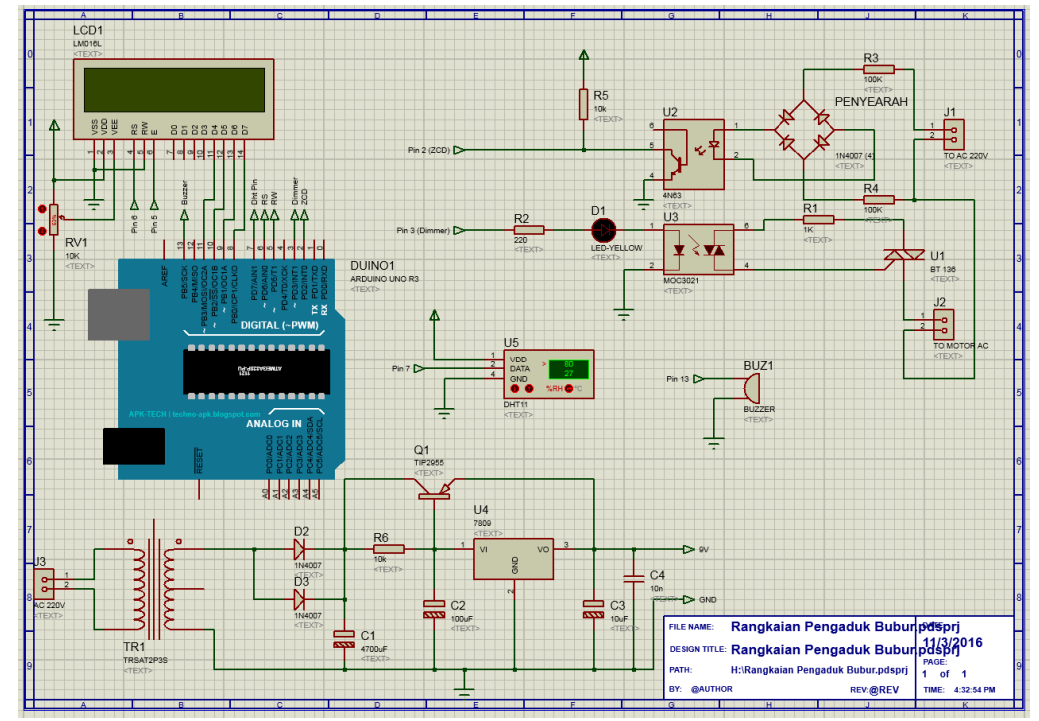

Gambar 16. Skematik alat pengaduk bubur otomatis

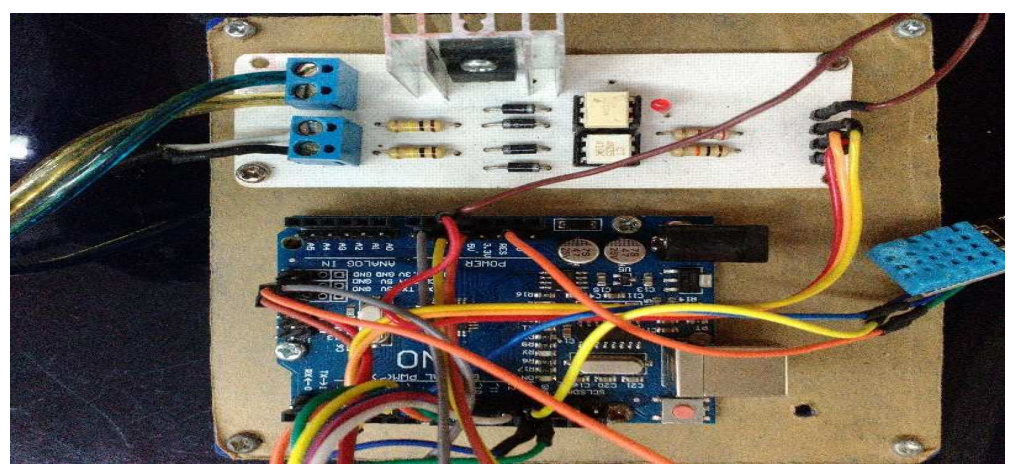

Gambar 17. Bentuk fisik rangkaian alat pengaduk bubur otomatis.

2. Hasil Pembuatan Software

Hasil pembuatan software yang telah sesuai dengan rancangan telah sesuai dengan rancangan. Hal tersebut dibuktikan dengan telah berfungsinya rangkaian hardware. (lampiran)

3. Konstruksi mesin alat pengaduk bubur otomatis.

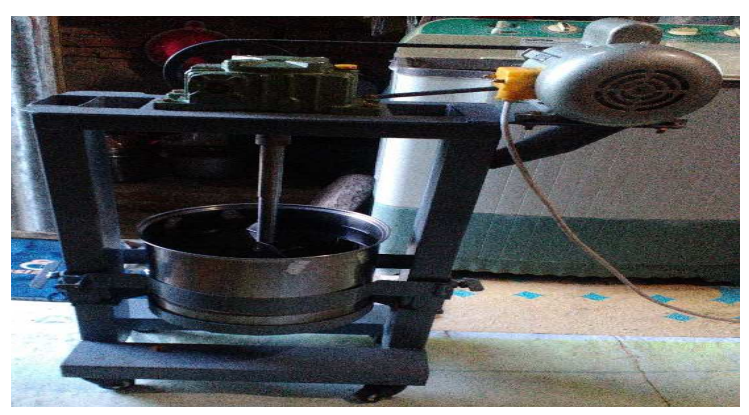

Gambar 18. Konstruksi mesin alat pengaduk bubur otomatis 
4. Pengujian dan Penerapan.

Pada tahap ini akan diterapkan alat pengaduk bubur otomatis untuk memasak bubur jagung. Kemudian menganalisis kenaikan suhu terhadap besar atau jumlah putaran/rotasi per menit (rpm) pengadukan bubur sehingga diperoleh waktu yang efisien dalam pemasakan bubur jagung. Hasil pengujian dan penerapan didapatkan data pengukuran seperti terlihat pada tabel 3. berikut :

Tabel 3 . Pengukuran Tegangan output sistem

\begin{tabular}{|c|c|c|c|c|c|}
\hline $\begin{array}{l}\mathrm{N} \\
\mathrm{O}\end{array}$ & $\begin{array}{c}\text { Suhu } \\
\text { Ruangan } \\
\left({ }^{\circ} \mathrm{C}\right) \\
\text { (Higromet } \\
\text { er) }\end{array}$ & $\begin{array}{l}\text { Tampil } \\
\text { an } \\
\text { Suhu } \\
\text { pada } \\
\text { LCD }\end{array}$ & Pulsa Output PWM & $\begin{array}{c}\text { Teganga } \\
\text { n Beban } \\
\text { (Vac) }\end{array}$ & $\begin{array}{l}\text { Kecepata } \\
\text { n motor }\end{array}$ \\
\hline 1 & 28 & 28 & \multirow{8}{*}{ (1) } & \multirow[t]{8}{*}{135} & \multirow[t]{8}{*}{ Rendah } \\
\hline 2 & 29 & 29 & & & \\
\hline 3 & 30 & 30 & & & \\
\hline 4 & 31 & 31 & & & \\
\hline 5 & 32 & 32 & & & \\
\hline 6 & 33 & 33 & & & \\
\hline 7 & 34 & 34 & & & \\
\hline 8 & 35 & 35 & & & \\
\hline 9 & 36 & 36 & \multirow{15}{*}{ 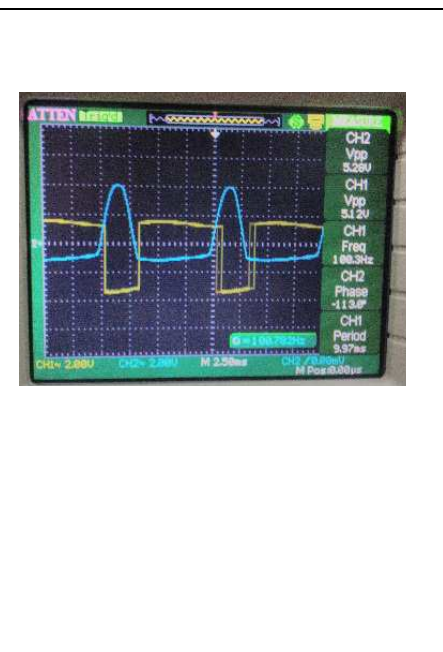 } & \multirow[t]{15}{*}{195} & \multirow[t]{15}{*}{ Sedang } \\
\hline 10 & 37 & 37 & & & \\
\hline 11 & 38 & 38 & & & \\
\hline 12 & 39 & 39 & & & \\
\hline 13 & 40 & 40 & & & \\
\hline 14 & 41 & 41 & & & \\
\hline 15 & 42 & 42 & & & \\
\hline 16 & 43 & 43 & & & \\
\hline 17 & 44 & 44 & & & \\
\hline 18 & 45 & 45 & & & \\
\hline 19 & 46 & 46 & & & \\
\hline 20 & 47 & 47 & & & \\
\hline 21 & 48 & 48 & & & \\
\hline 22 & 49 & 49 & & & \\
\hline 23 & 50 & 50 & & & \\
\hline 24 & 51 & 51 & \multirow{10}{*}{ 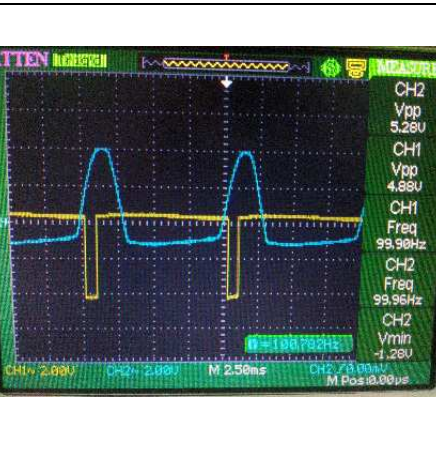 } & \multirow[t]{10}{*}{210} & \multirow[t]{10}{*}{ Tinggi } \\
\hline 25 & 52 & 52 & & & \\
\hline 26 & 53 & 53 & & & \\
\hline 27 & 54 & 54 & & & \\
\hline 28 & 55 & 55 & & & \\
\hline 29 & 56 & 56 & & & \\
\hline 30 & 57 & 57 & & & \\
\hline 31 & 58 & 58 & & & \\
\hline 32 & 59 & 59 & & & \\
\hline 33 & 60 & 60 & & & \\
\hline
\end{tabular}




\begin{abstract}
Berdasarkan pengukuran terlihat bahwa sensor yang digunakan mampu mendeteksi suhu dari suhu $28{ }^{\circ} \mathrm{C}$ sampai $100{ }^{\circ} \mathrm{C}$. Program yang dirancang dibuat untuk menghasilkan tegangan output berbeda sebagai sumber penggerak motor. Hasil pengujian dan pengukuran menunjukkan dengan tiga kecepatan berbeda.
\end{abstract}

\section{KESIMPULAN}

Berdasarkan pembahasan
pada bab-bab sebelumnya
mengenai rancang bangun alat
pengaduk bubur otomatis
menggunakan sensor suhu
berbasis arduino uno, diperoleh
kesimpulan sementara bahwa:

1. Rangkaian elektronika yang dibuat telah bekerja sesuai dengan rancangan alat pengaduk bubur otomatis.

2. Software yang dibuat telah berfungsi sebagai perangkat lunak pengendali mikroprosessor alat pengaduk bubur.

3. Konstruksi mesin pengaduk bubur otomatis mampu mengaduk bubur dengan bahan dasar $1 \mathrm{Kg}$.

4. Penerapan alat pada proses pembuatan bubur menghasilkan putaran motor pengaduk rendah pada suhu $28{ }^{\circ} \mathrm{C}$ s/d $35{ }^{\circ} \mathrm{C}$, sedang pada suhu $36{ }^{\circ} \mathrm{C}$ s/d 50 ${ }^{\circ} \mathrm{C}$ dan tinggi pada suhu $51{ }^{\circ} \mathrm{C}$ s/d $60{ }^{\circ} \mathrm{C}$.

\section{DAFTAR PUSTAKA}

[1] Abdul Kadir, 2013. Algoritma \& Pemrograman menggunakan Bahasa C dan C++. Yogyakarta : Andi

[2]_2014. Arduino

Panduan Mempelajari Aneka Proyek berbasis Mikrokontroler. Yogyakarta : Andi
[3] Afrie Setiawan. 2011. Mikrokontroler ATMEGA8535 dan ATMEGA16 dengan bascom-AVR. Yogyakarta : Andi

[4] Akhmad Insya Ansori.2013. Motor Induksi 1 Fasa. [diakses 15 November 2017]. http://insyaansori.blogspot.co.i d/2013/04/motor-induksi-1-fas a.html

[5] Andi hasad.2011. Operasi dan Aplikasi Triac. https://andihasad.files.wordpre ss.com/2011/12/operasi-dan-a plikasi-triac2.pdf

[6] Fatsecret. Bubur Jagung.[diakses : 30 April 2017]

https://www.fatsecret.co.id/kal ori-gizi/umum/bubur-jagung

[7] Happy Nugrahaning Widhi dan Heru Winarno.2014. Sistem Penyiraman Tanaman Anggrek Menggunakan Sensor kelembaban dengan Program Dhelpi 7 Berbasis Modul Arduino Uno R3.http://www.ejournal.undip. ac.id/index.php/gema teknolo gi/article/view/8807

[8] Herlan dan Briliant Adhi Prabowo.2009. Rangkaian Dimmer Pengatur Iluminasi Lampu Pijar Berbasis Internally trigger Triac. http://jurnal.informatika.lipi.go.i d/index.php/inkom/article/view $138 / 38$

[9] Joko priyanto, dkk. 2010. Singel Phase Motor.Depok: Departemen Teknik Elektro Fakultas Teknik Universitas Indonesia.

[10] Machmud Effendy.2009. Rancang Bangun Motor Induksi sebagai Generator (MISG) pada Pembangkit Listrik Tenaga Mikrohidro. 
Jurnal Teknik Elektro Universitas Muhammadiyah Malang. Vol.11 No.2, 2009.

[11] Priyono Yulianto. 2009. Mikrokontroler AT8951 sebagai Kendali Otomatis Mesin Pembuat Ceriping. http://ejournal.stt-wiworotomo. ac.id/index.php/iteks/article/vie $\mathrm{w} / 92$

[12] Susatyo Handoko dan Agung Nugroho .2007. Konverter
AC-AC Satu Fasa BerbasisMikrokontroler.

http://download.portalgaruda.o rg/article. php?article $=19928 \& \mathrm{v}$ al=1255\&title

[13] Yu,G. Pakbaz, K. and Heeger, A.J.1994.Optocoupler Made from Semiconducting Polymers. Jurnal of Electronic Materials. Vol.23 No. 9,1994. 